\title{
Assessing Receptivity to Empirically Supported Treatments in Rape Crisis Centers
}

\author{
Tonya Elaine Edmond \\ Rachel Voth Schrag
}

\begin{abstract}
Survivors of sexual violence are at risk for PTSD, depression, and anxiety. There are several empirically supported treatments (EST) that are effective for addressing these trauma symptoms; however, uptake of these ESTs among Rape Crisis Center (RCC) counselors is low. This research project sought to determine counselors' attitudes toward evidence-based practices (EBPs); their perceptions of the intervention characteristics of three specific ESTs: Prolonged Exposure (PE), Cognitive Processing Therapy (CPT) and Eye Movement Desensitization and Reprocessing Therapy; and differences in attitudes and perceptions based on agency setting (urban/rural) and counselor education. The Consolidated Framework for Advancing Implementation Science (CFIR) was used to construct a web-based survey to send to all RCCs in Texas $(n=83)$ resulting in an overall agency response rate of $72 \%(n=60)$ and responses from 76 counselors. Counselors' attitudes towards EBP and perspectives on specific ESTs suggest that dissemination and implementation efforts are needed within the RCC service sector to advance the uptake of $C P T, E M D R$ and $P E$.
\end{abstract}

Keywords: Trauma; evidence-based practice; PTSD; rape; rape crisis centers

Sexual violence, including child sexual abuse, rape, sexual assault, and threat of sexual assault, is a serious and widespread problem in the United States. Data from the National Intimate Partner and Sexual Violence Survey find that nearly 1 in 2 women and 1 in 5 men have experienced sexual violence other than rape, while 1 in 5 women and 1 in 71 men have experienced rape in their lifetime (Black et al., 2011). Survivors of sexual violence face serious mental health consequences including PTSD, depression, anxiety, and substance abuse (Jordan, Campbell, \& Follingstad, 2010).

Although there is a strong evidence base for the effectiveness of several interventions at reducing trauma-induced PTSD, depression, and anxiety in survivors of sexual violence, there is low utilization of these interventions in Rape Crisis Centers (RCCs; Edmond, 2004; Edmond, Lawrence, \& Voth Schrag, 2016). RCC counselors indicate they have limited familiarity with, knowledge about, or training in key evidence-based treatments (Edmond, 2004; Edmond et al., 2016). This is not unique to RCCs. Broadly speaking, there is an underutilization of evidence-based treatments in mental health service sectors. Numerous barriers to adoption of evidence-based treatments have been identified including: attitudes about evidence-based practice, intervention characteristics, costs, and access to training, supervision, and consultation (Aarons, 2004; Barnett et al., 2017; Beidas, Edmunds, Marcus \& Kendall, 2012; Dorsey et al., 2017; Ragavan, 2012). In order to promote the use of effective treatments for PTSD in RCCs, the current study sought to assess RCC counselors’ attitudes towards Evidence-Based Practices (EBPs) in general (i.e., how they

Tonya E. Edmond, PhD LCSW, is Associate Dean for Diversity, Inclusion, \& Equity and Associate Professor, George Warren Brown School of Social Work, Washington University in St. Louis, MO, 63130. Rachel J. Voth Schrag, PhD, LCSW, is an Assistant Professor, School of Social Work, University of Texas-Arlington, TX, 76019. 
feel about movement towards the use of EBPs), understand counselors' perceptions of specific Empirically Supported Treatments (ESTs) for PTSD, and evaluate any differences in attitudes and perceptions based on agency location (urban/rural) and counselor educational attainment.

\section{Background}

Rape Crisis Centers (RCCs) provide critical services to survivors of sexual violence, including crisis intervention, medical and legal advocacy, and counseling (Macy, Rizo, Johns, \& Ermentrout, 2013). RCCs are frequently independent agencies doing work in individual communities, with over 1,000 RCCs in the United States working together to run the National Sexual Assault Hotline (Rape, Abuse \& Incest National Network [RAINN], 2017). Evidence shows that survivors of sexual violence rate these services more favorably than those provided in other service sectors, including health care, legal, and other mental health sectors, and are more likely to access services from an RCC than another agency or system because they fear judgment or blame (Campbell \& Martin, 2001; Patterson, Greeson, \& Campbell, 2009). Thus, the RCC service sector serves a unique role in meeting survivor needs.

Systematic reviews of the adverse effects of childhood sexual abuse and sexual assault in adulthood reveal a broad constellation of psychological, behavioral, social, and physical health difficulties that negatively impact the lives of survivors (Bohn \& Holz, 1996; Campbell, Dworkin, \& Cabral, 2009; Jordan et al., 2010). PTSD, depression, anxiety, and substance abuse are among the most frequently reported mental health consequences and are often co-occurring (Chen \& Ullman, 2010; Jordan et al., 2010; Kilpatrick, Resnick, Ruggiero, Conoscenti, \& McCauley, 2007; Walsh, Galea, \& Koenen, 2012). Voth Schrag and Edmond (2015) found that for RCC counselors reducing symptoms of anxiety, depression, and PTSD were among the most frequently endorsed treatment goals. In their systematic review of the mental health impact of violence against women, Jordan and colleagues (2010) report that the most common mental health consequence of sexual violence is PTSD, with $33 \%-45 \%$ of women experiencing it in their lifetime. The number of rape survivors, combined with the incidence of PTSD among survivors, has led Rothbaum, Astin, and Marsteller (2005) to contend that "rape victims may constitute the largest number of PTSD sufferers in the United States" (p. 607). Many survivors with PTSD suffer with persistent and debilitating symptoms that can severely impact functioning and quality of life by significantly interfering with marital and social relationships, and work and school responsibilities (Foa, Keane, Friedman, \& Cohen, 2009). Furthermore, women who have had multiple life-time victimizations have been shown to present with more severe PTSD symptoms (Schaaf \& McCanne, 1998).

Research has also shown that PTSD increases the risk of substance abuse (Chilcoat \& Breslau, 1998; Kessler et al., 1997) and in the aftermath of rape, many survivors use drugs or alcohol as a coping strategy (Kaukinen \& Demaris, 2005; McFarlane et al., 2005). Largely because of the increased vulnerability produced by both the direct responses to trauma and the coping strategies survivors develop to confront it on a day-to-day basis, revictimization is also a serious concern. Untreated PTSD and substance abuse have both been found to increase risks of sexual and physical revictimization (Classen, Palesh, \& 
Aggarwal, 2005; Lalor \& McElvaney, 2010; Steel \& Herlitz, 2005). Women who have been sexually victimized once have a higher likelihood of being raped again by perpetrators who specifically target such vulnerability (Macy, 2007). Lalor and McElvaney (2010) found that adult survivors of child sexual abuse/assault with both PTSD and depression are 13.7 times more at risk for experiencing some type of interpersonal revictimization. Effectively treating PTSD enhances functioning and quality of life for survivors and serves as a form of prevention by reducing risks for future revictimization. In addition, the most effective evidence-based treatments for PTSD also have been shown to simultaneously and significantly reduce trauma-related depression and anxiety (Bisson \& Andrew, 2007).

Yet in the face of clear need, survivors access mental health services at a low rate, with estimates ranging from 16.1\% to 39-60\% (Campbell et al., 2009; Golding, Siegel, Sorenson, Burnam, \& Stein, 1989; Zinzow, Grubaugh, Frueh, \& Magruder, 2008). For those survivors who do access mental health services, there is a strong evidence base for a group of effective interventions to treat PTSD and related trauma symptoms (depression and anxiety) in sexual violence survivors. Cognitive Processing Therapy (CPT), Prolonged Exposure (PE) and Eye Movement Desensitization and Reprocessing Therapy (EMDR) have the strongest evidence for effectiveness in reducing PTSD symptomology among adult survivors. Meta-analyses comparing these treatments have found all to be effective, with none demonstrating superiority (Bisson \& Andrew, 2007; Regehr, Alaggia, Dennis, Pitts, \& Saini, 2013). These evidence-based interventions have been endorsed by several national guidelines for the treatment of PTSD including: the International Society for Traumatic Stress Studies (Foa et al., 2009), the Cochrane Database (Bisson \& Andrew, 2007), the U.S. Department of Veteran's Affairs (2017), the National Registry of EvidenceBased Programs and Practices of the Substance Abuse and Mental Health Services Administration (NREPP, 2017).

$\mathrm{PE}$ is an exposure-based psychotherapy approach for the treatment of trauma. PE starts with education about the therapy, common reactions to trauma, and PTSD. Clients are taught breathing retraining skills to facilitate relaxation. There are two types of exposure: In Vivo (real world practice) and Imaginal (repeatedly retelling the trauma narrative). In real world practice, the client approaches situations that although safe, the client has been avoiding because of trauma reminders. During Imaginal exposure, the client talks about the trauma memory repeatedly in the presence of the therapist to reduce fear and anxiety related to the memory. As homework, the client also listens to an audio recording of the trauma narrative (Foa et al., 2009).

CPT is a cognitive-based psychotherapy approach for the treatment of trauma. CPT starts with education about PTSD and trauma. The client is also asked to write a detailed trauma narrative that is read during therapy. The primary focus is on helping the client recognize the connections between thoughts and feelings and to develop skills to challenge negative or unhelpful thoughts and beliefs. Particular attention is given to beliefs related to safety, trust, control, self-esteem, and relationships. The client is given homework after each session to practice skills for challenging faulty thinking patterns (Resick \& Schnicke, 1993). 
EMDR is an integrative psychotherapy approach for the treatment of trauma. EMDR involves the use of an eight phase, three-pronged approach to treatment that targets past experience, current triggers, and future potential challenges. The eight phases include taking a good history and treatment planning, preparing the client for treatment, assessment, desensitization and reprocessing, installation of a positive cognition, body scan for physical sensations related to the trauma, closure, and reevaluation. Specific procedural steps are used to access and reprocess information that incorporate alternating bilateral eye movements, audio sounds or hand taps to help the client achieve a sense of integration and resolution of the traumatic experience (Shapiro \& Maxfield, 2002).

Despite the availability of ESTs to decrease PTSD among sexual violence survivors, and a clear link between PTSD and increased future sexual violence risk, there is low utilization of these treatments in the RCC service sector. In a nationwide sample of practitioners, Edmond (2004) found that, while 91\% of RCCs provided individual counseling to survivors of sexual assault, only $50 \%$ reported the use of at least one of these ESTs to address the mental health needs of survivors. There is a clear need for information regarding promotive factors and barriers to EST implementation in RCCs. Greater clarity about RCC counselors' attitudes about EST is needed to determine appropriate dissemination and implementation strategies.

\section{Attitudes Towards EBP and ESTs}

Factors at the individual, organizational, and system level influence the implementation and uptake of ESTs, including practitioner attitudes and perceptions (Aarons et al., 2012). A significant body of research has established practitioner attitudes as an important individual level factor that can influence EST implementation efforts, with positive attitudes towards EBP in general identified as a key practitioner level factor for successful implementation efforts (Aarons et al., 2012; Herschell, McNeil, \& McNeil, 2004; Palinkas et al., 2008). Aarons and colleagues (2010) identify a number of specific vectors through which practitioner attitudes to EBP can influence EBT uptake. They suggest that provider attitudes influence their choice to try new practices, the effectiveness of their implementation and fidelity to a model when using an EBP, and the likelihood of sustained use of an EBT. Additionally, research is emerging suggesting that attitudes towards specific ESTs play an important role in implementation. In a study of practitioner attitudes, Borntrager, Chorpita, Hilga-McMilan, and Weisz (2009) found that general EBP attitudes changed from pre to post-test based on factors such as the perceived adaptability of specific ESTs. Similarly, Reding, Chorpita, Lau, and Innes-Gomberg (2014) found that the appeal of a specific EST is related to practitioner uptake of that EST.

To promote the implementation and uptake of ESTs to treat PTSD within RCCs, this project sought to answer the following questions: (1) What are RCC counselors' attitudes toward EBP in general? (2) What are their perceptions of the intervention characteristics of three specific ESTs: PE, CPT and EMDR? (3) Are there differences in EST attitudes and perceptions based on agency setting (urban/rural) or counselor education? 


\section{Methods}

\section{Study Design}

Services provided by RCC counselors are critically important; however, much remains unknown about their attitudes towards EBP and specific ESTs for PTSD, and how those might differ by agency setting or counselor level of education. To gain perspective on these issues, a statewide web-based survey of Texas RCCs was administered during the summer/fall of 2013. The quantitative, cross-sectional survey was constructed with two different modules: one for executive directors and the other for practitioners providing individual and/or group counseling. The director module contained questions about respondent demographics, organizational characteristics, leadership style, and funding. The counselor module was comprised of questions about counselor characteristics and demographics; agency services provided and clients served; training obtained and desired; interventions employed; attitudes toward EBP in general; and views of three specific trauma-focused ESTs: cognitive processing therapy (CPT), Eye Movement Desensitization and Reprocessing (EMDR), and prolonged exposure (PE).

\section{Conceptual Model}

Evidence suggests that understanding counselor EBP attitudes in general as well as perceptions of specific ESTs can inform efforts to increase implementation of specific treatments. The Conceptual Framework for Implementation Research (CFIR), developed by Damschroder and colleagues (2009), merges aspects of 19 conceptual frameworks. It establishes five domains that together capture the key influences on the implementation of ESTs: intervention characteristics (evidence for the intervention, complexity of the intervention, adaptability of the intervention, and advantages the intervention has over others); outer setting (policies and incentives external to the agency as well as pressure from peers and clients); inner setting (characteristics of the organization setting and structure, culture, climate, and readiness for change); characteristics of individuals involved in implementation (their knowledge, skills, and attributes, and educational attainment), and the process of implementation. The CFIR provides a menu of potential areas for research with the expectation that scholars select constructs that are most salient to a particular study or setting to guide their evaluation of the implementation process. Within the intervention characteristics domain, the CFIR provides guidance regarding key characteristics that influence counselor perceptions and intervention uptake (Damschroeder et al., 2009). These include the source of the intervention (internal or external development), the evidence strength and quality for intervention effectiveness, the perceived relative advantage, the adaptability, trailability, complexity, design quality and packaging, and cost. The CFIR suggests that taken together, these indicators will impact counselor uptake of a new EST, and should be considered when designing an implementation strategy. The indicators of interest for this analysis were intervention characteristics, individual characteristics, and inner setting. The data comes from the counselor module. Data from the director module examined organizational level variables and were analyzed and reported separately. 


\section{Measures}

Evidence-Based Practice Attitudes Scale (EBPAS). The EBPAS (Aarons et al., 2010) was used to assess counselor attitudes towards EBP in general. The EBPAS includes 15 items measured on a 5 point Likert scale, spanning four lower-order subscales and one higher-order factor (Aarons et al., 2010). The four EBPAS subscales include Appeal, which assesses the likelihood of adopting an EST if it were intuitively appealing (i.e., if it makes sense, or colleagues are happy with it), Requirements, assessing the extent to which a provider would adopt based on employer or funder requirement, Openness, which assesses openness to new interventions (i.e., willingness to follow a treatment manual, the attractiveness of therapy developed by researchers), and Divergence, which assesses the extent to which a provider sees ESTs as less useful than clinical experience (i.e., the extent that they prefer clinical experience or view research-based treatments as not useful) (Aarons et al., 2010). In Aarons et al.’s (2010) national sample, the alpha reliability for the total scale was .76, and .81 for RCCs. The total EBPAS score with 15 items was used to compare the RCC sample to a normed sample of national mental health practitioners (Aarons et al., 2010). The same national normed sample is used for comparison with the RCC sample on the four original subscales: requirements, appeal, openness, and divergence.

Additional EBPAS subscales were added based on the expansion proposed by Aarons and colleagues (2012). While Aarons et al (2012) outlines eight additional subscales, we chose three to include in the current study due to their alignment with key CFIR constructs. These domains include Organizational Support, which assesses the perceived role of organizational training, CEUs, and assistance in the uptake of EBPs. Fit, which assesses the extent to which a treatment would be adopted if it felt right and met their clients' needs and treatment approach, and Limitations, which assesses the counselors' perception of the limits of EBP to meet client needs or the extent to which it creates barriers to treatment (Aarons et al., 2012). Aarons' and colleagues (2012) sample is used for comparison with the RCCs sample for these three subscales because they were not included in the nationally normed sample (Aarons et al., 2010).

Perceptions of Empirically Supported Treatments (PEST). The study team developed a single factor scale to assess counselor perceptions of three empirically supported treatments for survivors of sexual violence (PE, CPT, \& EMDR) based on the intervention characteristics domain of the CFIR (Damschroder et al., 2009; Edmond et al., 2016). For each EST, respondents were asked to provide their level of agreement on a 1-5 scale with ten questions tapping counselor perceptions regarding the evidence strength and quality, the relative advantage of that EST over other treatments, the adaptability, and complexity of the treatment, and the cost or resource constraints caused by the treatment (see Table 4). PEST items also assessed perceptions of acceptability, appropriateness, and the counselor's current level of knowledge regarding the EST procedures and techniques. To create a global measure of EST perceptions, items 4 and 10 were reverse-scored, and items were then totaled and divided by the number of items in the scale $(n=10)$. Higher scores indicate a stronger opinion of the EST in question. In the current sample, the reliability alpha for the PEST was .87 when administered for Prolonged Exposure, .86 for EMDR, and .91 for Cognitive Processing Therapy. 
Procedures

A comprehensive list of Texas RCCs was developed by the Texas Association Against Sexual Assault (TAASA), the state coalition $(n=83)$. Each executive director of every RCC in the state received an invitation through postal mail and e-mail to participate in the study. The invitation included an endorsement from TAASA. The executive director was asked to complete their module and to distribute the web-survey link to each of the eligible counseling staff to complete the counselor module. Each participant was given a \$20 gift card. Prior to data collection, approval was obtained from the Washington University IRB.

\section{Data Analysis}

Descriptive statistics including frequencies and central tendencies provide initial data regarding the sample and counselor perceptions. A chi-square test was used to assess differences in educational attainment by agency setting. Two-sample T-tests were used to assess differences in EBPAS total score and subscale scores between the RCC sample and Aarons et al. (2010) normed national sample of mental health service providers. T-tests and ANOVAs were used to assess differences in EBPAS and PEST scores by educational attainment and agency setting (rural/urban). Missing data occurred due to attrition over the course of the web-based survey and were treated on an available-case basis (Pigott, 2001).

Sample

In the overall study, the agency response rate was $72 \%$, with 60 RCCs providing a minimum of one survey from either an executive director or a counselor. Cases in which respondents indicated that counseling tasks were not a part of their job description were excluded from analysis. For this analysis the sample is comprised of respondents to the counselor-focused survey ( $\mathrm{n}=76)$.

\section{Results}

Counselor Demographics \& Characteristics. Counselors were overwhelmingly female (95\%), the majority identified as white (66.7\%), and had been at their current agency for an average of three years (range $=1$ month-18 years; see Table 1 ). Professionally, they were predominantly social workers (34.2\%), although many of those without an advanced degree identified more with their job title ('advocate,' 'counselor,' etc.) than a specific profession. Fifty-four percent had a master's degree or $\mathrm{PhD}, 22 \%$ had a bachelor's degree, and $24 \%$ had less than a bachelor's degree. Nearly sixty percent worked in urban or suburban settings (see Table 1 ). 
Table 1. Demographics for RCC Counselors $(n=76)$

\begin{tabular}{lrr}
\hline & Frequency (\%) & Mean(SD) \\
\hline Age & & $39.5(12.1)$ \\
Years of Experience & $7.8(6.8)$ \\
Agency Tenure & $3.0(3.5)$ \\
Gender (Female) & $71(94.7 \%)$ & \\
Race/Ethnicity & & \\
White & $17(66.7 \%)$ & \\
Hispanic/Latino & $3(4.7 \%)$ \\
African American/Black & $1(1.3 \%)$ \\
American Indian/Alaska Native & $1(1.3 \%)$ \\
Native Hawaiian/Pacific Islander & $3(4.0 \%)$ \\
More than one race & & \\
Professional Discipline & $26(34.2 \%)$ \\
Social Work & $23(30.3 \%)$ \\
Counseling & $6(7.9 \%)$ \\
Psychology & $3(4.0 \%)$ \\
Education & $2(2.6 \%)$ \\
Divinity/Theology & $1(1.3 \%)$ \\
Criminal Justice & $13(17.1 \%)$ \\
Job Title & $2(2.6 \%)$ \\
Other & & \\
Educational Attainment & $3(4.0 \%)$ \\
High School Degree & $15(19.7 \%)$ \\
Some College & $17(22.4 \%)$ \\
Bachelor's Degree & $39(51.3 \%)$ \\
Master's Degree & $2(2.6 \%)$ \\
Doctoral/Equivalent & \\
Agency Setting & $45(59.2 \%)$ \\
Urban/Suburban & $31(40.8 \%)$ \\
Rural &
\end{tabular}

Educational Attainment \& Agency Setting. Significant differences were observed in level of educational attainment between RCC counselors working in rural and urban areas. Among rural RCC counselors, $41.9 \%$ had less than a bachelor's degree, $22.6 \%$ had a bachelor's degree, and 35.5\% had an advanced degree. Comparatively, $11.1 \%$ of urban counselors had less than a bachelor's, $22.2 \%$ had a bachelor's degree, and $66.7 \%$ had an advanced degree $X^{2}(2)=10.67, \mathrm{p}<.01$.

Counselor Attitudes towards Evidence-Based Practice. The RCC sample had a significantly lower EBPAS total score compared $(M=2.57, \mathrm{SD}=.47)$ to Aarons and colleagues' (2010) normed national sample of mental health providers $(M=2.73, \mathrm{SD}=.49)$ $t(1147)=2.51, \mathrm{p}=.012$, indicating less willingness to adopt evidence-based practices (see table 2). RCC counselors also had significantly different outcomes on several EBPAS subscales compared to Aarons' 2010 and 2012 samples. Differences were observed between samples on requirements $t(1147)=2.87, \mathrm{p}=.004$; divergence $t(1147)=2.84, \mathrm{p}=.005$; organizational support $t(478)=4.72, \mathrm{p}=.001$; fit $t(\mathrm{df})=4.34, \mathrm{p}=.0001$; and limitations $t(478)=5.2, \mathrm{p}=.0001$ subscales. 
Table 2. Comparison of Attitudes towards EBP Among a National Provider and RCC Sample

\begin{tabular}{|c|c|c|c|c|}
\hline & $\begin{array}{c}\text { National MH } \\
\text { Provider Sample }^{1} \\
\end{array}$ & $\begin{array}{c}\text { RCC Sample } \\
(n=60)\end{array}$ & \multirow{2}{*}{$\begin{array}{c}\text { Two sample } \\
\text { t-test }\end{array}$} & \multirow[b]{2}{*}{ p-value } \\
\hline & Mean (SD) & Mean (SD) & & \\
\hline EBPAS Total Score & $2.73(.49)$ & $2.57(.47)$ & 2.51 & $.012 *$ \\
\hline Requirements & $2.41(.99)$ & $2.78(.97)$ & 2.87 & $.004 * *$ \\
\hline Appeal & $2.91(.68)$ & $2.98(.66)$ & 0.79 & .430 \\
\hline Openness & $2.76(.75)$ & $2.57(.70)$ & 1.95 & .052 \\
\hline Divergence & $1.25(.70)$ & $0.99(.72)$ & 2.84 & $.005^{* *}$ \\
\hline Organizational Support & $3.07(.82)$ & $2.54(.86)$ & 4.72 & $.0001^{* * *}$ \\
\hline Fit & $2.90(.75)$ & $2.46(.72)$ & 4.34 & $.0001 * * *$ \\
\hline Limitations & $1.28(.91)$ & $0.65(.75)$ & 5.20 & $.0001^{* * *}$ \\
\hline $\begin{array}{l}\text { Notes. For requiremen } \\
\text { limitations, } n=420 \mathrm{MH}\end{array}$ & $\begin{array}{l}\text { l, openness, \& } \\
\text { Health, RCC }\end{array}$ & $\begin{array}{l}\text { ence, } n=1,08 \\
\text { Crisis Cente }\end{array}$ & $\begin{array}{l}\text { org. support, } \\
05,{ }^{* *} \mathrm{p}<.01\end{array}$ & $\begin{array}{l}\text { and } \\
{ }^{*} \mathrm{p}<.001\end{array}$ \\
\hline
\end{tabular}

Within the RCC sample, no significant differences were observed in EBPAS total or subscale scores between rural and urban counselors (see Table 3). When comparing counselors by education level (no degree, bachelor's, advanced), differences were observed in EBPAS total score $F(2)=8.55, \mathrm{p}=.001$; Appeal $F(2)=6.58, \mathrm{p}=.003$; Limitations $F(2)=5.72, \mathrm{p}=.006$; Fit $F(2)=5.72, \mathrm{p}=.006$; and Organizational Support $F(2)=11.04$, $\mathrm{p}=.000$. Counselors without bachelor's degrees tended to have the most negative views of evidence-based practices, while those with advanced degrees had more positive views.

Table 3. EBPAS Score by Agency Setting and Counselor Education

\begin{tabular}{|c|c|c|c|c|c|c|}
\hline Item & $\begin{array}{c}\text { Total Sample } \\
\text { Mean } \\
(n=60\end{array}$ & $\begin{array}{l}\text { Rural } \\
\text { Mean } \\
(n=25)\end{array}$ & $\begin{array}{l}\text { Urban } \\
\text { Mean } \\
(n=35)\end{array}$ & $\begin{array}{c}\text { Less than } \\
\text { BA } \\
(\mathbf{n}=15)\end{array}$ & $\begin{array}{c}\text { BA } \\
(n=10)\end{array}$ & $\begin{array}{c}\text { Masters/PhD } \\
(\mathbf{n}=35)\end{array}$ \\
\hline EBPA Total Score & 2.57 & 2.55 & 2.59 & 2.4 & 2.7 & $2.6^{*}$ \\
\hline Appeal & 2.98 & 2.97 & 2.99 & 2.5 & 3.2 & $3.1^{* *}$ \\
\hline Requirements & 2.78 & 2.76 & 2.80 & 2.8 & 3.1 & 2.7 \\
\hline Openness & 2.57 & 2.55 & 2.59 & 2.3 & 2.8 & 2.6 \\
\hline Divergence & .99 & .96 & 1.01 & 1.1 & 1.0 & .96 \\
\hline Limitations & .65 & .765 & .565 & 1.2 & .33 & $.49 * *$ \\
\hline Fit & 2.46 & 2.33 & 2.54 & 1.8 & 2.3 & $2.8 * * *$ \\
\hline Org. Support & 2.54 & 2.44 & 2.60 & 1.76 & 3.1 & $2.7 * * *$ \\
\hline
\end{tabular}

Counselor Perceptions of ESTs for PTSD. Counselors had the most positive perceptions of CPT, followed by Prolonged Exposure and EMDR (see Table 4). CPT was rated the most highly across CFIR domains, including evidentiary support, relative advantage, adaptability, and resource constraints, as well as on acceptability, appropriateness, and current level of knowledge. Counselors endorsed EMDR and CPT equally on complexity. Counselors had mixed perceptions of PE and EMDR across CFIR domains, with PE scoring higher than EMDR on adaptability and EMDR scoring higher than PE on evidentiary support, relative advantage, appropriateness, and complexity. 
Table 4. Perceptions of EST Scale (1=Disagree Strongly-5=Agree Strongly)

\begin{tabular}{|c|c|c|c|}
\hline & $\begin{array}{l}\text { PE } \\
\text { Mean } \\
\text { Score }\end{array}$ & $\begin{array}{l}\text { EMDR } \\
\text { Mean } \\
\text { Score }\end{array}$ & $\begin{array}{l}\text { CPT } \\
\text { Mean } \\
\text { Score }\end{array}$ \\
\hline $\begin{array}{l}\text { 1. I have a good understanding of the procedures and } \\
\text { techniques involved in [the EST]. }\end{array}$ & 2.9 & 2.6 & 3.3 \\
\hline $\begin{array}{l}\text { 2. There is a high quality, strong base of evidence } \\
\text { demonstrating the effectiveness of [the EST] in treating } \\
\text { PTSD in rape \& sexual abuse survivors. }\end{array}$ & 3.4 & 3.4 & 3.6 \\
\hline $\begin{array}{l}\text { 3. The quality and strength of the evidence base around the } \\
\text { effectiveness of [the EST] makes me want to use it with } \\
\text { my clients. }\end{array}$ & 3.3 & 3.4 & 3.6 \\
\hline $\begin{array}{l}\text { 4. The procedures and techniques involved in [the EST] are } \\
\text { too complex to use with clients at a sexual assault } \\
\text { program. }\end{array}$ & 2.9 & 2.8 & 2.8 \\
\hline $\begin{array}{l}\text { 5. [The EST] could be adapted, modified, and tailored to } \\
\text { meet the needs of our clients within our program. }\end{array}$ & 3.5 & 3.3 & 3.6 \\
\hline $\begin{array}{l}\text { 6. [The EST] has advantages over other treatments for } \\
\text { PTSD that make it a better choice for sexual trauma } \\
\text { survivors. }\end{array}$ & 3.1 & 3.2 & 3.4 \\
\hline $\begin{array}{l}\text { 7. I believe the use of [the EST] is an acceptable treatment } \\
\text { option for treating sexual trauma survivors with PTSD. }\end{array}$ & 3.4 & 3.5 & 3.6 \\
\hline $\begin{array}{l}\text { 8. Within our program, [the EST] would be viewed as an } \\
\text { appropriate treatment option for our clients. }\end{array}$ & 3.1 & 3.3 & 3.6 \\
\hline $\begin{array}{l}\text { 9. With training and supervision I would be likely to use } \\
\text { [the EST] with my clients on an ongoing basis when } \\
\text { appropriate. }\end{array}$ & 3.4 & 3.4 & 3.7 \\
\hline $\begin{array}{l}\text { 10. It is not feasible to use [the EST] in our program } \\
\text { because of resource constraints and training } \\
\text { requirements. }\end{array}$ & 3.1 & 3.0 & 2.8 \\
\hline
\end{tabular}

Among RCC counselors, significant differences in perceptions of EMDR were seen between those working in rural and urban areas, with urban counselors rating EMDR significantly higher than rural counselors $t(51)=2.23, p=.031$ (see Table 5 ). No differences were seen between urban and rural counselors on their perceptions of PE or CPT. Across all three ESTs, counselors with less than a bachelor's degree had more positive views of the interventions than those with a bachelor's degree. Approximately 38\% $(n=23)$ of counselors reported having a "fair amount" or a "great deal" of training in CPT, compared to $17 \%$ in $\mathrm{PE}$ and $8 \%$ in EMDR. 
Table 5. Perceptions of ESTs by agency setting and counselor education

\begin{tabular}{lccc}
\hline & $\begin{array}{c}\text { Prolonged } \\
\text { Exposure }\end{array}$ & EMDR & $\begin{array}{c}\text { Cognitive } \\
\text { Processing }\end{array}$ \\
\hline Total Sample Mean & 3.2 & 3.1 & 3.3 \\
Rural & 3.3 & 2.9 & 3.2 \\
Urban & 3.2 & $3.3^{*}$ & 3.3 \\
Less than BA & 3.2 & 3 & 3.2 \\
BA & 3.1 & 2.9 & 3 \\
Masters/PhD & 3.2 & 3.2 & 3.4 \\
\hline${ }^{*}<$ .05 & & & \\
\hline
\end{tabular}

\section{Discussion}

The mental health effects of sexual violence are well-documented, and effective treatments for PTSD exist that can help promote healing for survivors. However, there has not been sufficient uptake of these treatments by counselors in RCCs, who are viewed as the primary response system in place to support victims of sexual violence. Although RCC counselors had a lower overall EBPAS score than Aaron's 2010 nationally normed sample of mental health providers, an examination of the seven subscales provides some useful information. The three subscales that the national sample more strongly endorsed were Openness, Organizational Support and Fit. These subscales reflect that the mental health counselors were more open to new interventions, were more influenced toward adoption of ESTs by organizational support, and had a sense that the intervention felt right and would meet their clients' needs. Interestingly, RCC counselors were significantly more likely to see fewer limitations in the use of ESTs and the mental health providers were significantly more likely to see ESTs as less useful than clinical experience (Divergence). RCC counselors were also more likely to adopt an EST if a supervisor, agency, or state required it compared to the national sample. Both groups had comparable scores on the Appeal subscale, reflecting equal likelihood of adopting an EST if it were intuitively appealing. This suggests that RCC counselors could be receptive to adopting ESTs since they see few limitations and value them as much as clinical experience, if it is an appealing EST and adoption is reinforced by organizational or funder requirements. These differences could be partly attributed to educational differences between the samples, with over $80 \%$ of Aaron's sample holding advanced degrees, and less than 3\% having less than a bachelor's degree.

We found significant differences in counselor level of educational attainment between rural and urban settings, with rural RCCs having significantly fewer counselors with advanced degrees and more counselors without a degree. They are providing critical individual and group counseling services to highly vulnerable survivors of sexual assault in geographic areas that often have no other options for mental health services. While it is clear that these counselors are the best and often the only resource available for vulnerable survivors, it is essential that we consider strategies for putting the best available treatments safely in the hands of counselors with bachelor's degrees as well as those without degrees.

Given that the trauma-focused ESTs in question are all designed and implemented with advanced clinicians in mind, and that in some cases advanced degrees are required in order 
for counselors to receive training in the EST, strategies for working in rural settings, in which providers face both geographic and educational barriers to EST adoption, are needed. The fact that rural settings are nearly four times as likely as urban settings to be providing counseling through a non-degreed counselor, suggests that one such strategy would be identifying effective trauma treatments that can be implemented without a college education or with only a bachelor's degree. Both CPT and EMDR have developed modified versions of these interventions that have been used by paraprofessionals to effectively treat PTSD and related trauma symptoms (Bass et al., 2013; Jarero, Amaya, Givaudan, \& Miranda, 2013; Plouffe, 2007).

Evidence from the developing world suggests that this may be an option for under resourced areas in the United States. In the Democratic Republic of Congo, Bass and colleagues (2013) tested the implementation of a modified (cognitive only) form of CPT with psychosocial assistants. These paraprofessionals had experience with survivors of sexual violence, as well as case management and supportive counseling, but no educational credentials. Using the group-based protocol, they were able to achieve significant reductions in PTSD, depression, and anxiety after just two weeks of training. Similarly, Jarero and colleagues (2013) piloted a randomized clinical trial to evaluate the efficacy of a modified form of EMDR created for paraprofessionals (EMDR-PROPARA), for responding to acute traumatic stress. The outcomes showed that PROPARA was significantly more effective in reducing post-traumatic stress symptoms than supportive counseling. RCC counselors are first responders who engage with survivors immediately after a sexual assault, and many of them are paraprofessionals, therefore, EMDRPROPARA might be a viable intervention option for this service sector. Given the limited amount of evidence available on these modified paraprofessional versions of EMDR and $\mathrm{CPT}$, their application in low-resourced, rural RCCs would require careful evaluation to determine acceptability, treatment fidelity, effectiveness, and feasibility.

Other strategies for working in rural settings might include greater utilization of technology to deliver training, supervision and consultation to support the implementation of evidence-based interventions by counselors in rural communities with less than a master's degree. Social work might also adopt a strategy that medicine has employed to recruit doctors and nurses into rural communities and advocate for school loan forgiveness for MSWs to incentivize them to work in these low-resourced settings. An advantage to this strategy would be the ability to not only use evidence-based treatments, but also to strengthen the training and supervision of those with less education in their use.

While there were significant differences in educational attainment between providers in rural and urban settings, there was no difference between urban and rural providers on their EBPAS scores, suggesting that counselors from across service settings are equally interested in incorporating evidence-based approaches into their practice. There were however, significant differences by educational attainment. Across EBPAS subscales, counselors with advanced and bachelor's degrees had more positive attitudes towards EBPs in general than those without degrees. However, when assessing their perceptions of specific ESTs (e.g., CPT, EMDR and PE), those with advanced degrees and those without any degree had consistently stronger endorsements than those with bachelor's degrees. Taken together, these findings suggest that implementation efforts aimed at RCC providers 
could be successful, and should make special consideration of differences in provider educational attainment and agency setting.

Counselors were asked to provide their perspectives on three ESTs for PTSD among sexual trauma survivors: PE, EMDR, and CPT. Among these three ESTs, CPT was the most favorably endorsed, with the highest ratings on measures of evidentiary support, comparative advantage, adaptability, acceptability, and appropriateness. Counselor reactions to these intervention characteristics suggest that CPT may be the best candidate for implementation and uptake in RCCs. Therefore, implementation strategies to support the adoption of CPT in RCCs need to be identified and tested.

Counselors' perceptions of EMDR and PE were more mixed, with more favorable perceptions of PE overall, but with EMDR scoring higher than PE on a number of factors, including appropriateness, comparative advantage, and perceived complexity. Urban providers also had significantly stronger overall perceptions of EMDR than rural providers. Given the familiarity and receptivity among urban providers, as well as the presence of higher numbers of master's level counselors in these RCCs, dissemination of information and education efforts might have the biggest impact for uptake if offered in urban settings.

RCC counselors reported a lack of familiarity with the procedures, techniques, and evidence base supporting all three ESTs, as well as mixed opinions regarding their acceptability and feasibility. The most frequently endorsed response to questions regarding counselor perceptions of the three ESTs was "uncertain,” suggesting that counselors lack key knowledge about these ESTs. As such, efforts focused on dissemination of information regarding the procedures, effectiveness, and evidence base for these interventions could support counselors in making informed decisions around obtaining training and implementing these practices in their agencies. Given that a practitioner's perception of the empirical support for an intervention significantly predicts the chance of receiving training and using that intervention, implementation efforts could start with dissemination by educating the RCC workforce on the merits of these interventions (Allen, Gharagozloo, \& Johnson, 2011). Community-based therapists with training in these interventions could volunteer to provide in-service informational sessions or introductory workshops at individual RCCs, or at regional and state coalition meetings or conferences. This would give RCC counselors the information needed to decide whether it is a treatment approach that they would be willing to invest time and money into acquiring. That said, the standard costs of training for these ESTs would be prohibitively expensive for many RCC counselors given the typical salaries within this setting. Consequently, trainers are encouraged to offer reduced costs or pro bono trainings and consultation to support advancing uptake of these treatments in RCCs.

It is also important to acknowledge that while PTSD is prevalent and needs to be addressed, many survivors seeking services do not have PTSD, but are struggling with other trauma symptoms such as depression, anxiety, low self-esteem, a lack of selfconfidence, self-harming behaviors and suicidal ideation, and/or relationship difficulties. Although the evidence-based treatments for PTSD discussed in this paper are robust and tend to produce symptom relief across a number of symptom domains, they may not be the best intervention choice for every survivor. There may be other evidence-based treatments 
that would be a better fit given a particular survivor's presenting concerns for example, Interpersonal Therapy for depression and relationship difficulties, Dialectical Behavioral Therapy for reducing self-harming behaviors, or Cognitive Behavioral Therapy or Mindfulness Based Stress Reduction for reducing anxiety and increasing positive coping. Intervention selection should be driven by the treatment needs and goals developed collaboratively between the counselor and the survivor. Evidence-based practice includes not just scientific evidence of effectiveness, but also practitioner expertise and client preferences (Sackett et al., 1996).

Limitations. A number of limitations should be considered when evaluating the findings of the current study. These data comprise a small sample of counselors in a single state, all working at agencies that are members of the state coalition, and may not reflect the population of RCC providers across the country. Additionally, due to the small sample size, multiple bivariate analyses were run on the same sample and potentially important control variables (for example, potential differences in education between mental health providers and RCC providers) were not included. The scale used to measure counselor perceptions of specific ESTs was developed for the current study, and although it is informed by theory and evidence, it should be replicated with larger samples in order to assess its validity, psychometric properties, and reliability.

Conclusion. Participants' attitudes towards evidence-based practices and perspectives on specific ESTs suggest that dissemination and implementation efforts should be made within the RCC service sector to advance the uptake of CPT, EMDR and PE to address the impact of PTSD among sexual trauma survivors. However, given that CPT was perceived most positively by RCC counselors in terms of its intervention characteristics, initial implementation efforts could begin there. Implementation strategies to support the adoption of CPT in this low-resourced, decentralized, nonprofit service sector could yield knowledge that would be transferrable to other similarly structured settings. The observed differences in attitudes and perceptions by educational attainment and geographic setting suggest that specific attention is needed to identify implementation strategies and intervention modifications to provide rural counselors and those without advanced degrees with training on the strongest, most effective interventions possible.

\section{References}

Aarons, G. A. (2004). Mental health provider attitudes toward adoption of evidencebased practice: The Evidence-Based Practice Attitude Scale (EBPAS). Mental Health Services Research, 6(2), 61-74. doi: https://doi.org/10.1023/B:MHSR.0000024351.12294.65

Aarons, G., Glisson, C., Hoagwood, K., Kelleher, K., Landsverk, J., Cafri, G., \& The Research Network on Youth Mental Health. (2010). Psychometric properties and United States National Norms of the Evidence-Based Practice Attitude Scale (EBPAS). Psychological Assessments, 22(2), 356-365. doi: https://doi.org/10.1037/a0019188

Aarons, G., Glisson, C., Green, P., Hoagwood, K., Kelleher, K., Landsverk, J., \& the Research Network on Youth Mental Health. (2012). The organizational social 
context of mental health services and clinician attitudes toward evidence-based practice: A United States national study. Implementation Science, 7(56), 1-15.

Allen, B., Gharagozloo, L., \& Johnson, J. C. (2011). Clinician knowledge and utilization of empirically supported treatments for maltreated children. Child Maltreatment, 17(1), 11-21. doi: http://dx.doi.org/10.1177/1077559511426333

Barnett, M., Brookman-Frazee, L., Regan, J., Saifan, D., Stadnick, N., \& Lau, A. (2017). How intervention and implementation characteristics relate to community therapists' attitudes toward evidence-based practices: A mixed-methods study. Administration and Policy in Mental Health and Mental Health Services Research, online first, 1-14. doi: https://doi.org/10.1007/s10488-017-0795-0

Bass, J. K., Annan, J., McIvor Murray, S., Kaysen, D., Griffiths, S., Cetinoglu, T., . . . Bolton, P. A. (2013). Controlled trial of psychotherapy for Congolese survivors of sexual violence. New England Journal of Medicine, 368(23), 2182-2191. doi: https://doi.org/10.1056/NEJMoa1211853

Beidas, R. S., Edmunds, J. M., Marcus, S. C., \& Kendall, P. C. (2012). Training and consultation to promote implementation of an empirically supported treatment: A randomized trial. Psychiatric Services, 63(7), 660-665. doi: https://doi.org/10.1176/appi.ps.201100401

Bisson, J., \& Andrew, M. (2007). Psychological treatment of post-traumatic stress disorder (PTSD). Cochrane Database of Systematic Reviews, 3(CD003388 ). doi: https://doi.org/10.1002/14651858.CD003388.pub3

Black, M. C., Basile, K. C., Breiding, M. J., Smith, S. G., Walters, M. L., Merrick, M. T.,... Stevens, M. R. (2011). The national intimate partner and sexual violence survey (NISVS): 2010 Summary report. Atlanta, GA: National Center for Injury Prevention and Control, Centers for Disease Control and Prevention.

Bohn, D. K., \& Holz, K. A. (1996). Sequelae of abuse: Health effects of childhood sexual abuse, domestic battering, and rape. Journal of Nurse-Midwifery, 41(6), 442-456. doi: https://doi.org/10.1016/S0091-2182(96)80012-7

Borntrager, C., Chorpita, B., Hilga-McMilan, C., \& Weisz, J. (2009). Provider attitudes toward evidence-based practices: Are the concerns with the evidence or with the manuals? Psychiatric Services, 60(5), 677-681. doi: https://doi.org/10.1176/ps.2009.60.5.677

Campbell, R., Dworkin, E., \& Cabral, G. (2009). An ecological model of the impact of sexual assault on women's mental health. Trauma, Violence, \& Abuse, 10(6), 225246. doi: https://doi.org/10.1177/1524838009334456

Campbell, R., \& Martin, P. Y. (2001). Services for sexual assault survivors: The role of rape crisis centers. In C.M. Renzetti, J. L. Edelson, \& R. K. Bergen (Eds.), Sourcebook on violence against women (pg. 227-241). Thousand Oaks, CA: Sage. 
Chen, Y., \& Ullman, S. (2010). Women's reporting of sexual and physical assaults to police in the National Violence Against Women Survey. Violence Against Women, 16(3), 262-279. doi: https://doi.org/10.1177/1077801209360861

Chilcoat, H. D., \& Breslau, N. (1998). Posttraumatic stress disorder and drug disorders: testing causal pathways. Archives of General Psychiatry, 55(10), 913-917. doi: https://doi.org/10.1001/archpsyc.55.10.913

Classen, C., Palesh, O., \& Aggarwal, R. (2005). Sexual revictimization: A review of the empirical literature. Trauma, Violence, \& Abuse, 6(2), 103-129. doi: https://doi.org/10.1177/1524838005275087

Damschroder, L. J., Aron, D. C., Keith, R. E., Kirsh, S. R., Alexander, J., A., \& Lowery, J. C. (2009). Fostering implementation of health services research findings into practice: A consolidated framework for advancing implementation science. Implementation Science, 4, 50-65. doi: https://doi.org/10.1186/1748-5908-4-50

Dorsey, S., Pullmann, M. D., Kerns, S. E., Jungbluth, N., Meza, R., Thompson, K., \& Berliner, L. (2017). The juggling act of supervision in community mental health: Implications for supporting evidence-based treatment. Administration and Policy in Mental Health and Mental Health Services Research, online first, 1-15. doi: https://doi.org/10.1007/s10488-017-0796-Z

Edmond, T. (2004, September). Theoretical and intervention preferences of service providers addressing violence against women: A national survey. Paper presented at the 9th International Conference on Family Violence, San Diego, CA.

Edmond, T., Lawrence, K., \& Voth Schrag, R. (2016). Perceptions and use of EMDR therapy in rape crisis centers. Journal of EMDR Practice \& Research, 10(1), 23-32. doi: https://doi.org/10.1891/1933-3196.10.1.23

Foa, E. B., Keane, T. M., Friedman, M. J., \& Cohen, J. A. (2009). Effective treatments for PTSD: Practice guidelines from the International Society for Traumatic Stress studies (2nd ed.). NY: Guilford Press.

Golding, J., Siegel, J., Sorenson, S., Burnam, M., \& Stein, J. (1989). Social support sources following sexual assault. Journal of Community Psychology, 17, 92-107. doi: https://doi.org/10.1002/1520-6629(198901)17:1<92::AIDJCOP2290170110>3.0.CO;2-E

Herschell, A. D., McNeil, C. B., \& McNeil, D. W. (2004). Clinical child psychology's progress in disseminating empirically supported treatments. Clinical Psychology: Science and Practice, 11, 267-288. doi: https://doi.org/10.1093/clipsy.bph082

Jarero, I., Amaya, C., Givaudan, M., \& Miranda, A. (2013). EMDR individual protocol for paraprofessional use: A randomized controlled trial with first responders. Journal of EMDR Practice and Research, 7(2), 55-64. doi: https://doi.org/10.1891/19333196.7.2.55

Jordan, C. E., Campbell, R., \& Follingstad, D. (2010). Violence and women's mental health: The impact of physical, sexual, and psychological aggression. Annual Review 
of Clinical Psychology, 6, 607-628. doi: https://doi.org/10.1146/annurev-clinpsy090209-151437

Kaukinen, C., \& Demaris, A. (2005). Age at first sexual assault and current substance use and depression. Journal of Interpersonal Violence, 20, 1244-1270. doi: https://doi.org/10.1177/0886260505277732

Kessler, R. C., Crum, R. M., Warner, L. A., Nelson, C. B., Schulenberg, J., \& Anthony, J. C. (1997). Lifetime co-occurrence of DSM-III-R alcohol abuse and dependence with other psychiatric disorders in the national comorbidity survey. Archives of General Psychiatry, 54(4), 313-321. doi: https://doi.org/10.1001/archpsyc.1997.01830160031005

Kilpatrick, D., Resnick, H. S., Ruggiero, K., Conoscenti, M., \& McCauley, J. (2007). Drug-facilitated, incapacitated, and forcible rape: A national study. Washington D.C.: Department of Justice. Retrieved from https://www.ncjrs.gov/pdffiles1/nij/grants/219181.pdf

Lalor, K., \& McElvaney, R. (2010). Child sexual abuse, links to later sexual exploitation/high-risk sexual behavior, and prevention/treatment programs. Trauma, Violence, \& Abuse, 11(4), 159-177. doi: https://doi.org/10.1177/1524838010378299

Macy, R. J. (2007). A coping theory framework toward preventing sexual revictimization. Aggression and Violent Behavior, 12(2), 177-192. doi: https://doi.org/10.1016/j.avb.2006.09.002

Macy, R. J., Rizo, C. F., Johns, N. B., \& Ermentrout, D. M. (2013). Directors' opinions about domestic violence and sexual assault service strategies that help survivors. Journal of Interpersonal Violence, 28(5), 1040-1066. doi: https://doi.org/10.1177/0886260512459375

McFarlane, J., Malecha, A., Gist, J., Watson, K., Batten, E., Hall, I., \& Smith, S. (2005). Intimate partner sexual assault against women and associated victim substance use, suicidality, and risk factors for femicide. Issues in Mental Health and Nursing, 26, 953-967. doi: https://doi.org/10.1080/01612840500248262

NREPP (2017). National registry of evidence-based programs and practices. Retrieved from https://samhsa.gov/nerpp

Palinkas, L., Schoenwald, S., Hoagwood, K., Landsverk, J., Chorpita, B., \& Weisz, J. (2008). An ethnographic study of implementation of evidence-based treatments in child mental health: First steps. Psychiatric Services, 59, 738-746. doi: https://doi.org/10.1176/ps.2008.59.7.738

Patterson, D., Greeson, M., \& Campbell, R. (2009). Understanding rape survivors' decisions not to seek help from formal social systems. Health \& Social Work, 34(2), 127-136. doi: https://doi.org/10.1093/hsw/34.2.127

Pigott, T. D. (2001). A review of methods for missing data. Educational Research and Evaluation, 7(4), 353-383. doi: https://doi.org/10.1076/edre.7.4.353.8937 
Plouffe, K. A. (2007). Paraprofessional intervention using a cognitive processing protocol. Clinical Case Studies, 6(4), 348-361. doi: https://doi.org/10.1177/1534650106291415

Raghavan, R. (2012). The role of economic evaluation in dissemination and implementation research. In R. Brownson, G. Colditz, \& E. Proctor (Eds.), Dissemination and implementation research in health: Translating science to practice (pp. 94-113). New York: Oxford University Press. doi: https://doi.org/10.1093/acprof:oso/9780199751877.003.0005

Rape, Abuse, and Incest National Network [RAINN]. (2017). Rape, Abuse, and Incest National Network: Sexual Assault Service Providers. Retrieved from https://www.rainn.org/sexual-assault-service-providers

Reding, M., Chorpita, B., Lau, A., \& Innes-Gomberg, D. (2014). Providers' attitudes toward evidence-based practices: Is it just about providers, or do practices matter too? Administration and Policy in Mental Health, 41(6), 767-776. doi: https://doi.org/10.1007/s10488-013-0525-1

Regehr, C., Alaggia, R., Dennis, J., Pitts, A., \& Saini, M. (2013). Interventions to reduce distress in adult victims of rape and sexual violence: A systematic review. Research on Social Work Practice, 23(3), 257-265. doi: https://doi.org/10.1177/1049731512474103

Resick, P. A., \& Schnicke, M. K. (1993). Cognitive processing therapy for rape victims: A treatment manual. Newbury Park, CA: Sage.

Rothbaum, B. O., Astin, M. C., \& Marsteller, F. (2005). Prolonged exposure versus eye movement desensitization and reprocessing (EMDR) for PTSD victims. Journal of Traumatic Stress, 18, 607-616. doi: https://doi.org/10.1002/jts.20069

Sackett, D. L., Rosenberg, W. M., Gray, J. M., Haynes, R. B., \& Richardson, W. S. (1996). Evidence-based medicine: What it is and what it isn't. British Medical Journal, 312(1), 71-72. doi: https://doi.org/10.1136/bmj.312.7023.71

Schaaf, K., \& McCanne, T. (1998). Relationship of childhood sexual, physical, and combined sexual and physical abuse to adult victimization and posttraumatic stress disorder. Child Abuse and Neglect, 22(11), 1119-1133. doi: https://doi.org/10.1016/S0145-2134(98)00090-8

Shapiro, F., \& Maxfield, L. (2002). Eye movement desensitization and reprocessing: Information processing in the treatment of trauma. Journal of Clinical Psychology, 58, 933-946. doi: https://doi.org/10.1002/jclp.10068

Steel, J., \& Herlitz, C. (2005). The association between childhood and adolescent sexual abuse and proxies for sexual risk behavior: A random sample of the general population of Sweden. Child Abuse \& Neglect, 29(10), 1141-1153. doi: https://doi.org/10.1016/j.chiabu.2004.10.015

Walsh, K., Galea, S., \& Koenen, K. C. (2012). Mechanisms underlying sexual violence exposure and psychosocial sequelae: A theoretical and empirical review. Clinical 
Psychology: Science \& Practice, 19(3), 260-275. doi: https://doi.org/10.1111/cpsp.12004

Department of Veterans Affairs (2017). The Management of Posttraumatic Stress Disorder and Acute Stress Disorder. Washington D.C: Department of Veterans Affairs. Retrieved from www.healthquality.va.gov

Voth Schrag, R., \& Edmond. T. (2015, January). Frequently reported treatment goals and issues assessed among clinicians in rape crisis centers. Society for Social Work and Research Annual Meeting, New Orleans, LA.

Zinzow, H., Grubaugh, A., Frueh, B., \& Magruder, K. (2008). Sexual assault, mental health, and service use among male and female veterans seen in Veterans Affairs primary care clinics: A multi-site study. Psychiatry Research, 159(1-2), 226-236. doi: https://doi.org/10.1016/j.psychres.2007.04.008

Author note: Address correspondence to: Tonya E. Edmond, PhD, LCSW, George Warren Brown School of Social Work, Washington University in St. Louis, MO 63130 tee1@wustl.edu 